\title{
The Effect of Irradiation Wavelength on the Quality of CdS Nanocrystals Formed Directly into PMMA Matrix
}

\author{
Despina Fragouli, ${ }^{*},{ }^{\dagger}$ Pier P. Pompa,${ }^{\dagger}$ Maria Kalyva,${ }^{\dagger}$ Gianvito Caputo,${ }^{\ddagger}$ Leander Tapfer,${ }^{\S}$ \\ Roberto Cingolani, ${ }^{\perp}$ and Athanassia Athanassiou ${ }^{\dagger, *}$ \\ Center for Bio-Molecular Nanotechnologies (CBN) of IIT@UniLe, via Barsanti, 73010, Arnesano (LE), Italy, \\ National Nanotechnology Laboratory (NNL), CNR - Istituto di Nanoscienze, via per Arnesano, 73100, Lecce, Italy, \\ ENEA, Centro Ricerche Brindisi, SS7 Appia Km 706, I-72100, Brindisi, Italy, and IIT- Italian Institute of \\ Technology, Via Morego 30, 16163, Genova, Italy
}

Received: April 15, 2010; Revised Manuscript Received: July 19, 2010

\begin{abstract}
UV laser irradiation of PMMA films containing Cd thiolate precursors results in the spatially selective formation of $\mathrm{CdS}$ crystalline nanoparticles in the host matrix. Here we investigate the effect of the irradiation wavelength on the quality of the formed nanocrystals. Fluorescence topography and XPS studies reveal that the polymer matrix contributes to the trap states formation on the surface of the nanocrystals. When the latter are formed upon irradiation at $266 \mathrm{~nm}$, they exhibit broad emission spectra, ascribed to the high degree of photodegradation of the polymer. In contrast, the irradiation at $355 \mathrm{~nm}$ does not chemically modify the matrix, resulting in the formation of $\mathrm{CdS}$ nanocrystals with narrow emission, i.e. high emission quality. This is further confirmed by fluorescence lifetime topography studies giving a mean fluorescence nanocrystal lifetime as short as $200 \mathrm{ps}$ at room temperature. Thus, the optimized combination of irradiation wavelength with polymer matrix gives nanocomposite materials incorporating nanocrystals of high quality, ready to be used in various optical applications.
\end{abstract}

\section{Introduction}

Semiconductor nanocrystals (NCs) exhibit unique photophysical characteristics, due to the quantum confinement effect. $^{1-5}$ In particular, their size-dependent optical properties, such as high emission quantum yields, narrow emission bands, and tunable emission/absorption spectra, have received much attention in recent years. ${ }^{6-9}$ These properties can be exploited in several technological applications by embedding the NCs into polymeric matrices, thus producing nanocomposite materials. ${ }^{10-12}$ By the careful selection of both components, the formed nanocomposites can exhibit novel characteristics, since the above-mentioned properties of the inorganic NCs can be combined with the properties of the polymers, resulting in highly processable materials with increased stability. ${ }^{13,14}$

For different applications, the patterned formation of welldispersed NCs into polymers is highly requested, since it provides spatially selective tailoring of specific properties of the nanocomposites. Indeed, on one hand a good dispersion of the NCs optimize their quantum size effect, meaning the control of their emission properties. On the other hand, the localization of the NCs in specific sides of the polymer provides the possibility of the direct incorporation of the nanocomposites in various advanced technological applications, such as emission devices, sensors, directional biological growth, etc.

Our approach involves the localized in situ formation of NCs inside polymer matrices by UV laser irradiation of polymerprecursor films. This method, has proved to be more efficient and faster than other in situ preparation methods in this field,

\footnotetext{
* Author for correspondence. Telephone: +39 0832 295719. Fax +39 0832 295730. E-mail: despina.fragouli@iit.it; despina.fragouli@unisalento.it.

CBN of IIT.

*NNL, CNR.

$\S$ ENEA.

${ }^{\perp}$ IIT.
}

such as the thermal annealing, where the NCs localization is impossible, ${ }^{15,16}$ or the time-consuming and hazardous $\mathrm{H}_{2} \mathrm{~S}$ gas treatment of polymer-precursor resins. ${ }^{12,17}$ Our recent studies revealed that the UV irradiation of metal precursor-TOPAS polymer films results in CdS NCs, with dimensions extending from the quantum size effect range to the bulk, depending on the number of the incident pulses and on the wavelength of the irradiation. The quality of the formed NCs is generally studied by their emission characteristics, indicating that the broader the emission spectra, the higher the number of the trap states on their surfaces. ${ }^{18-21}$ Although the polymer TOPAS has intriguing physical properties for a number of applications, ${ }^{22}$ it demonstrated some drawbacks in experimental trials, performed in our laboratories, with electrospinning and two-photon photopolymerization. These two fields are very promising for future applications of the presented method, taking advantage of the in situ photopolymerized $\mathrm{CdS}$ nanocomposite micropatterns, or the formation of electrospun nanocomposite nanofibers with accurate control of the NCs size upon UV irradiation. On the other hand, since the PMMA polymer is an excellent candidate for the above-mentioned and numerous other applications, we performed the following study of the CdS NCs formation with UV irradiation of metal precursors in this matrix, and we proved that size-tuned NCs can be formed also in PMMA. However, intense deteriorations (broadening) were observed in the emission spectra of the NCs formed in PMMA compared to TOPAS upon increasing the number of pulses. ${ }^{19}$ This observation left open questions regarding the trap states formed at the nanoparticles surfaces and their dependence on the surrounding matrix.

Herein, for the further and more precise control of the quality of the formed NCs in PMMA matrix, we present a study of CdS-PMMA nanocomposites created upon different irradiation wavelengths (266 and $355 \mathrm{~nm}$ ) of precursor-PMMA films. We 
show that it is possible to have excellent NCs quality with sizes even in the bulk region, (higher than $6-7 \mathrm{~nm}$ ) upon irradiation at $355 \mathrm{~nm}$, revealing that the laser wavelength in combination with the polymer matrix plays a critical role in the quality of the produced NCs. This is proved by the confocal imaging and fluorescence lifetime mapping, showing that the CdS NCs emission quality is very high in the case of irradiation with the $355 \mathrm{~nm}$, while the irradiation with $266 \mathrm{~nm}$ causes polymer photoproducts that increase the trap state emission, as confirmed by a detailed XPS study.

\section{Experimental Section}

Author: The metal precursor used is the cadmium bisdodecanethiolate $\mathrm{Cd}\left(\mathrm{SC}_{12} \mathrm{H}_{25}\right)_{2}$, (C12), while the polymer is poly(methyl methacrylate) (PMMA). The chemical reaction formula for the preparation of the precursor is described in detail in ref 15 . A portion of the metal thiolate, $20 \%$ by weight, was mixed with polymer, $80 \%$ by weight, and then diluted in toluene. The solution was sonicated for $30 \mathrm{~min}$ in order to obtain the maximum dispersion of the insoluble $\mathrm{C} 12$. The solution was finally cast in a Petri capsule, and after the evaporation of the toluene, the nanocomposite film was formed.

For the formation of the NCs in the polymer matrix, the films were irradiated with various numbers of pulses of a Nd:YAG laser (Quanta-Ray PRO-290-30, Spectra Physics) operating at the third and fourth harmonics, (355 and $266 \mathrm{~nm}$, repetition rate 10 and $2 \mathrm{~Hz}$ respectively, pulse duration $8 \mathrm{~ns}$ ). The laser beam was focused perpendicularly onto the surface of the samples. The series of irradiations were performed under air atmosphere. The laser fluence and repetition rate were low enough to prevent any macroscopic and microscopic structural change $^{18,20}$ on the surface of the polymer, but efficient for the formation of NCs.

UV-visible absorption spectra were obtained using a UV-vis-NIR spectrophotometer (Cary 5000-Varian). Spatially resolved photoluminescence measurements and fluorescence lifetime imaging microscopy (FLIM) experiments have been performed on the irradiated films by a confocal microscope (Leica TCS-SP5 AOBS). The excitation wavelength $\left(\lambda_{\text {exc }}\right)$ was $405 \mathrm{~nm}$, and the irradiated areas were observed through a $20 \times$ 0.70 NA objective, $40 \times 1.25 \mathrm{NA}$, or $63 \times 1.40 \mathrm{NA}$ oil immersion objectives. For spectral analysis, the $\lambda_{\text {exc }}$ was 405 $\mathrm{nm}$, and the emission bandwidth was $20 \mathrm{~nm}$.

Low-magnification transmission electron microscopy (TEM) images of the laser-synthesized NCs were recorded with a Jeol Jem 1011 microscope operating at an accelerating voltage of $100 \mathrm{kV}$. The samples for TEM analysis were prepared by dropping dilute solutions of the irradiated part of the samples dissolved in chloroform onto carbon-coated copper grids, and then allowing the solvent to evaporate. Next, the grids were immediately transferred to the TEM microscope and analyzed.

The photoemission experiments were carried out in an ultrahigh vacuum (UHV) system, which consisted of a fast entry specimen assembly, a sample preparation, and an analysis chamber with a base pressure $<5 \times 10^{-10} \mathrm{mbar}$. The system was equipped with a SPECS LHS-10 hemispherical electron analyzer and a twin anode X-ray gun. A constant analyzer pass energy of $E_{\mathrm{p}}=97 \mathrm{eV}$ and the unmonochromatized $\mathrm{Mg} \mathrm{K} \alpha$ $(1253.6 \mathrm{eV})$ line were used in all X-ray photoelectron spectroscopy (XPS) measurements. The XPS core level spectra were analyzed with a fitting routine, which can decompose each spectrum into individual mixed Gaussian-Lorentzian peaks after a Shirley background subtraction. Regarding the measurement errors, for the XPS core level peaks we estimate that for a good

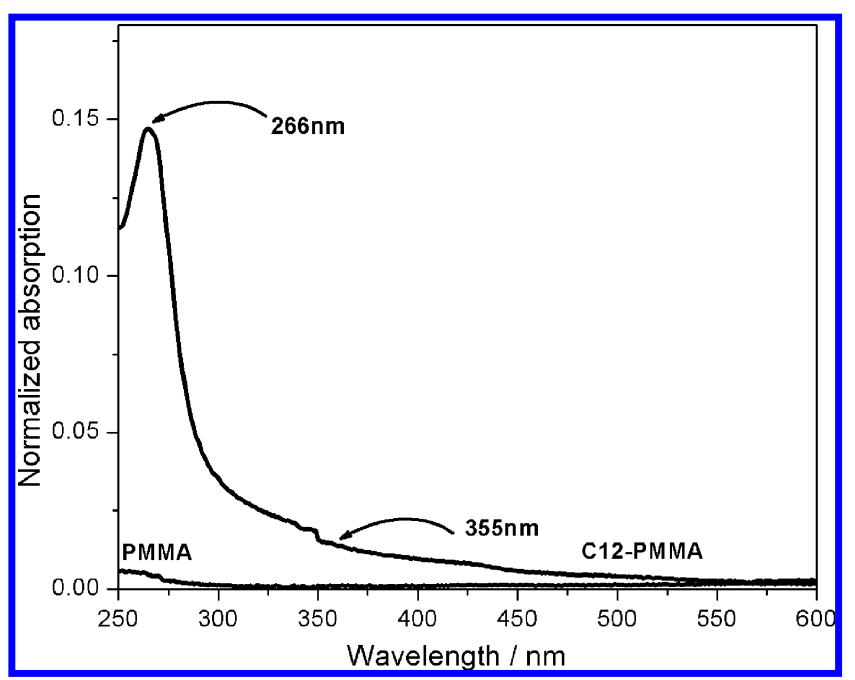

Figure 1. Absorption spectra of the PMMA and of the C12-PMMA solutions.

signal-to-noise ratio, errors in peak positions can be $\pm 0.05 \mathrm{eV}$. The binding energy (BE) scale in XPS measurements was calibrated by assigning the main $\mathrm{C} 1 \mathrm{~s}$ peak at $284.6 \mathrm{eV} .^{23}$

\section{Results and Discussion}

The irradiation of the C12-PMMA films was performed using two different wavelengths (266 and $355 \mathrm{~nm}$ ). As shown in Figure 1, their absorption efficiency is sufficiently lower at $355 \mathrm{~nm}$. In the case of the bare polymer, the absorption efficiency is close to zero for both wavelengths.

The irradiation of the precursor embedded in a matrix at these wavelengths is proved to cause the formation of $\mathrm{CdS} \mathrm{NCs}$, with their size depending on the number of the incident pulses. ${ }^{19-21}$ Moreover, the NCs formation strongly depends on the irradiation wavelength, under the same laser fluence. Specifically, it has been found that the formation of the CdS upon irradiation at $266 \mathrm{~nm}$ is fast, due to the high absorption efficiency of the precursor, causing the $\mathrm{C}-\mathrm{S}$ bond breakage (eq 1).

$$
\begin{aligned}
& \mathrm{Cd}\left(\mathrm{SC}_{12} \mathrm{H}_{25}\right)_{2}+\text { polymer } \stackrel{\mathrm{UV}}{\longrightarrow} \mathrm{CdS}+\text { polymer }+ \\
& \qquad \mathrm{S}\left(\mathrm{C}_{12} \mathrm{H}_{25}\right)_{2}
\end{aligned}
$$

On the other hand, the formation of the NCs under $355 \mathrm{~nm}$ irradiation is much slower, since the absorption efficiency of the precursor at this wavelength is smaller. ${ }^{21}$ However, in both cases the CdS size tuning is achieved by changing the number of the incident pulses (Figure 2, and ref 19), while the structural characteristics of the polymer matrix remain macroscopically/ microscopically unaffected. ${ }^{20}$

Moreover, emission studies of the size-tuned CdS NCs in PMMA matrix revealed that, upon increasing the number of incident laser pulses, there is a broadening of the NCs spectra when the wavelength $266 \mathrm{~nm}$ is used, ${ }^{19}$ whereas upon irradiation at $355 \mathrm{~nm}$ the emission spectra remain narrow (see Supporting Information, Figure S1). Since these spectra differences become more intense in the region of the bulk NCs sizes, we present next a study on NCs with sizes in this region, in order to clarify the mechanisms that led to this selective spectra broadening.

Figure $3 \mathrm{a}$ shows the fluorescence images of a C12-PMMA film irradiated with 80 laser pulses of fluence, $F=20 \mathrm{~mJ} / \mathrm{cm}^{2}$, at $\lambda=266 \mathrm{~nm}$, and the corresponding emission taken from 




Figure 2. TEM images of the CdS NCs formed after irradiation of the C12-PMMA films with: (a) 300 and (b) 3000 laser pulses at 355 nm, with fluence $20 \mathrm{~mJ} / \mathrm{cm}^{2}$. The two insets correspond to higher magnifications.

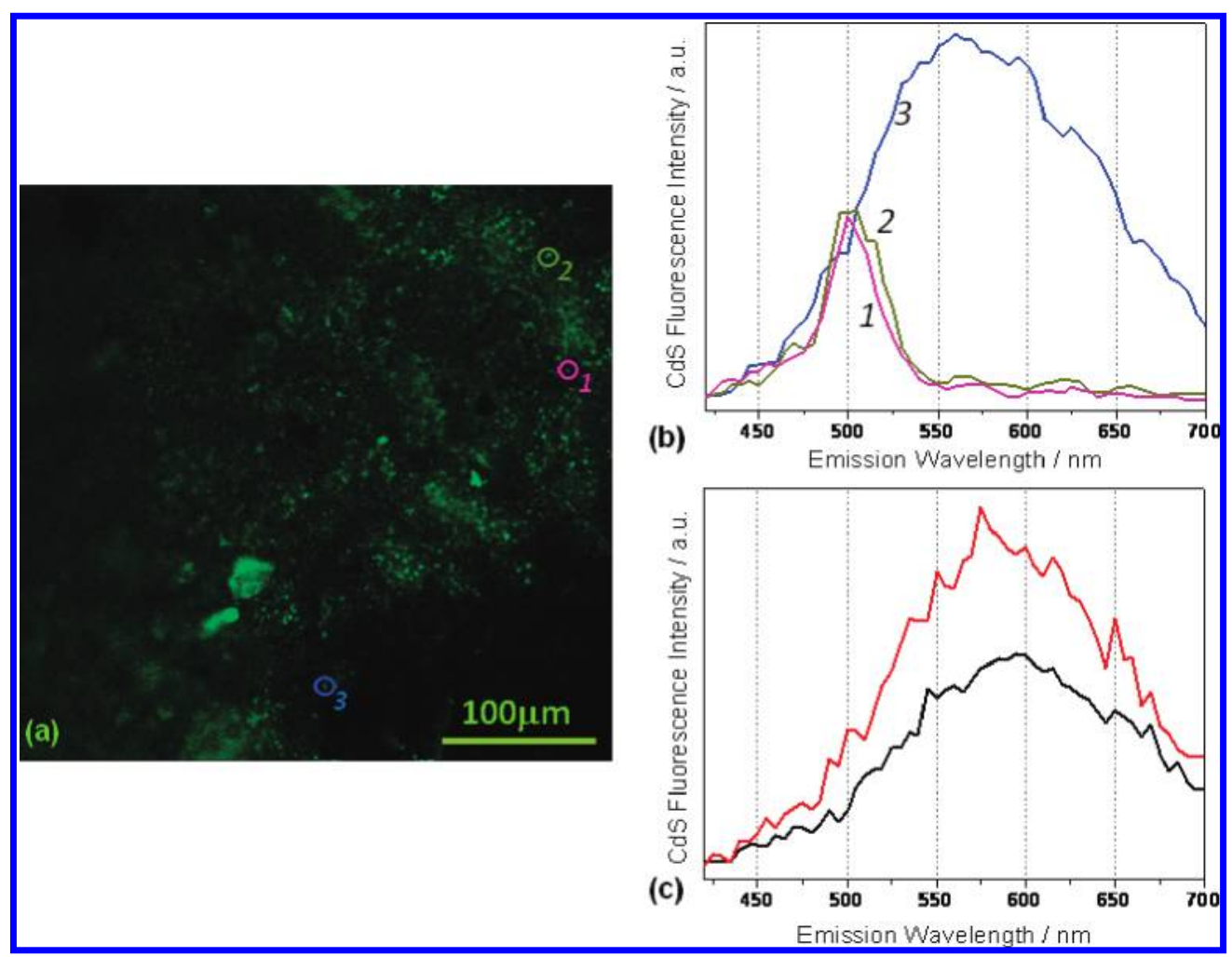

Figure 3. (a) Fluorescence image of the C12-PMMA film after irradiation at $266 \mathrm{~nm}$ with 80 incident pulses of fluence $F=20 \mathrm{~mJ} / \mathrm{cm}^{2}$. (b) Emission spectra of selected areas of the image; each curve corresponds to the marked area of (a) with the same color/number. (c) Emission spectra of selected areas of the C12-PMMA film after irradiation at $266 \mathrm{~nm}$ with 80 incident pulses of fluence $F=50 \mathrm{~mJ} / \mathrm{cm}^{2}$.

various areas of the film. The emission spectra show the existence of few $\mathrm{CdS} \mathrm{NCs}$ emitting at the bulk region (NCs diameter higher than $7 \mathrm{~nm}$ ) with an emission peak around 500 $\mathrm{nm}$ and a spectral width of $\sim 32 \pm 1 \mathrm{~nm}$ (Figure $3 \mathrm{~b}$ ), while many areas exhibit a very broad emission peaking at $\sim 550 \mathrm{~nm}$ (Figure 3b, blue line), representative of the trap states emission formed on the surface of the NCs. ${ }^{24-27}$ By increasing the laser fluence and keeping stable the number of the pulses $(F=50$ $\mathrm{mJ} / \mathrm{cm}^{2}, 80$ pulses) the characteristic emission of the NCs is no more evident in the irradiated area, while the trap state emission is dominant (Figure 3c). This indicates that the laser irradiation at $266 \mathrm{~nm}$ results in the formation of NCs with trap states on their surface, an evidence that becomes clearer as the incident fluence increases.

On the other hand, the emission study of the films irradiated with $355 \mathrm{~nm}$ shows that the dominant emission derives from $\mathrm{CdS}$, with characteristic narrow emission $(22 \pm 4 \mathrm{~nm}$ bandwidth) around $500 \mathrm{~nm}$, indicating the existence of higher quality of NCs with sizes in the bulk region. Specifically, in Figure 4 we report the emission spectra of various areas of the C12-PMMA fluorescence image taken after irradiation of the sample with 2000 pulses at $355 \mathrm{~nm}$ and fluence $65 \mathrm{~mJ} / \mathrm{cm}^{2}$. Exactly the same behavior is observed after irradiation of the films with the same fluence but different number of incident pulses (1000 and 3000 pulses), or with lower laser fluencies $\left(20 \mathrm{~mJ} / \mathrm{cm}^{2}\right)$ revealing that the irradiation with this specific laser wavelength does not affect the system and does not result in trap states on the surface of the formed NCs (data shown in Supporting Information, Figure S2,3). The defects on the surface of the NCs affect not only the width and peak of the emission but also their fluorescence lifetime. Specifically, the lifetime is an indication of the presence of surface trap states and consequently an indication of the quality of the NCs. Hence, high quality $\mathrm{CdS}$ NCs with low density of trap states exhibit strong band edge emission with typical lifetime from several picoseconds to several nanoseconds. On the other hand, low quality NCs have intense deep trap emission with the fluorescence lifetime to reach values up to microseconds. ${ }^{26}$ Accordingly, for the further characterization of the formed bulk NCs and of the resulting nanocomposite films, the fluorescence lifetime is studied, using the fluorescence lifetime imaging microscopy (FLIM) technique at room temperature. In particular, 


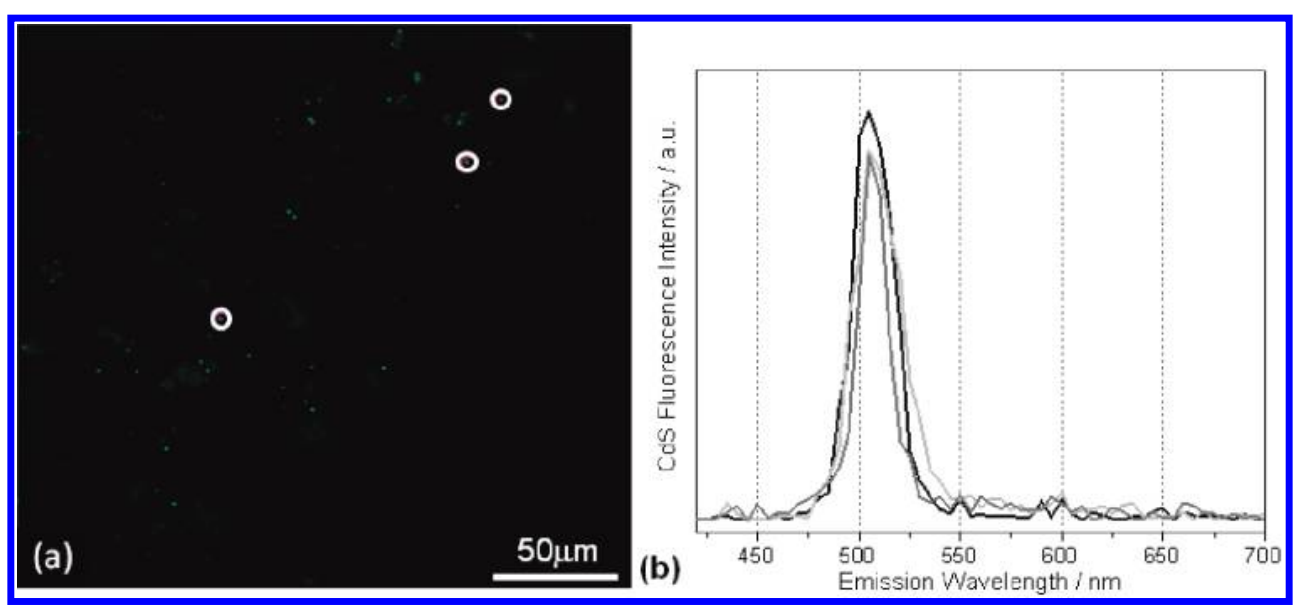

Figure 4. (a) Fluorescence image of the C12-PMMA film after irradiation at $355 \mathrm{~nm}$ with 2000 incident pulses of fluence $F=65 \mathrm{~mJ} / \mathrm{cm}^{2}$. (b) Emission spectra of selected cycled areas of the image (a).

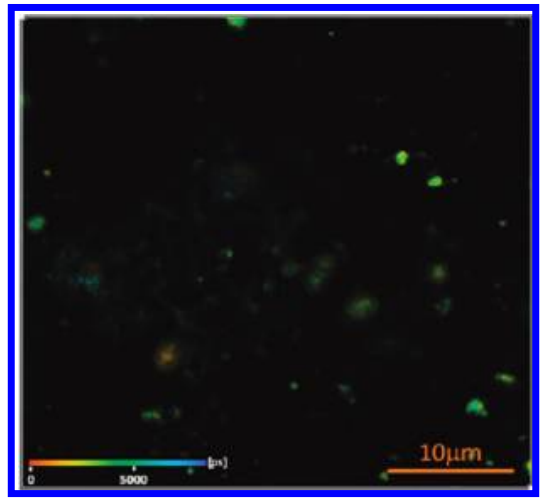

Figure 5. Fluorescence lifetime topography of the C12-PMMA film before any irradiation.

the irradiated area containing $\mathrm{CdS}$ NCs was excited with a pulsed laser emitting at $405 \mathrm{~nm}$, while the fluorescence emission was collected at various ranges between 480 and $640 \mathrm{~nm}$ depending on the spectral area of interest in each case. Figure 5 demonstrates the fluorescence lifetime topography of the precursor-PMMA film before any irradiation. The emission was collected at the spectral range of $500 \mathrm{~nm}-640 \mathrm{~nm}$, and it is shown that the mean fluorescence lifetime is in the range of some ns.

When this film is irradiated with 2000 pulses at $355 \mathrm{~nm}(F$ $=65 \mathrm{~mJ} / \mathrm{cm}^{2}$ ), the lifetime topography is changed, and by focusing in a narrow spectral range $(500 \pm 20 \mathrm{~nm})$ can be easily revealed a number of CdS NCs in the matrix with a mean fluorescence lifetime of about $200 \pm 20$ ps (Figure 6, orange spots), while at the rest of the area there are species with mean lifetime around 2-3 ns. The latter may correspond to formed NCs with deep trap states on their surfaces, ${ }^{26}$ while the former may correspond to NCs having shallow surface trap states. ${ }^{28}$ The density of the NCs formed upon irradiation at $266 \mathrm{~nm}$, which emit at $500 \mathrm{~nm}$ and have mean lifetime at $200 \pm 20 \mathrm{ps}$, was found to be much smaller, indicating that the number of the formed NCs of high quality is lower (see Supporting Information, Figure S4). These results are in agreement with the static fluorescence study, where it is shown that the quality of the formed NCs in terms of surface defects is low when they are formed upon irradiation with $266 \mathrm{~nm}$.

A comparison with the literature shows that our measured value of the CdS lifetime is significantly longer than the near band edge emission observed in single CdS NCs $(\sim 5-30$ ps). ${ }^{29-31}$ On the other hand, it is in agreement with measurements done on CdS nanosheets ${ }^{32}$ and is shorter than that measured for the bulk CdS (500 ps to $1 \mathrm{~ns}),{ }^{32-34}$ both at low temperatures $(\sim 8-15 \mathrm{~K})$. In addition, the mean fluorescence lifetime of colloidal nanocrystals is in the range of nanoseconds, ${ }^{35,36} \mathrm{a}$ value much higher than the one presented. However, more meaningful is the comparison with reported values measured on nanocomposite films of CdS in PMMA at room temperature, where the mean fluorescence lifetime was found to be some tens of nanoseconds, ${ }^{37}$ a value significantly higher than the reported one. Consequently, the obtained value indicates that the reported method for CdS NCs formation in PMMA films upon laser irradiation at $355 \mathrm{~nm}$ results in high-quality NCs, and moreover into high-quality nanocomposites.

The only variable condition in this study is the irradiation wavelength, and to summarize, it is shown that the photons at $266 \mathrm{~nm}$ are highly absorbed by the precursor-PMMA films, and the formed bulk NCs have increased numbers of trap states on their surfaces compared to the NCs formed upon irradiation at $355 \mathrm{~nm}$. This observation guides us to the conclusion that the surface environment of the NCs is different; thus, the polymer matrix is affected in different ways by each of the two irradiation wavelengths.

For the detailed investigation of the matrix role in the quality of the NCs, X-ray photoelectron spectroscopy measurements of the C12-PMMA films before and after irradiation with the two different wavelengths $(355 \mathrm{~nm}, 1500$ pulses, fluence 20 $\mathrm{mJ} / \mathrm{cm}^{2}$ and $266 \mathrm{~nm}, 80$ pulses, fluence $50 \mathrm{~mJ} / \mathrm{cm}^{2}$ ) were performed. As shown in Figure 7 , the XPS C1s spectrum obtained for the C12-PMMA film at $355 \mathrm{~nm}$ is almost identical to the one of the not irradiated film. On the contrary, the spectrum of the film irradiated at $266 \mathrm{~nm}$ exhibits many differences. After the deconvolution of the XPS spectra, the comparison of the intensity of the individual peaks showed a decrease of the amount of the $-\mathrm{C}=\mathrm{O}, \mathrm{C}-\mathrm{O}-\mathrm{Cd},(\mathrm{BE} \approx 288.2$ $\left.\mathrm{eV}^{38}\right)$, and $-\mathrm{C}=\mathrm{O}-\mathrm{O}(\mathrm{BE} \approx 289.6 \mathrm{eV})$ groups, and $\mathrm{a}$ pronounced increase of the amount of the $\mathrm{C}-\mathrm{C}$, and $\mathrm{C}-\mathrm{H}$ bonds, $\left(\mathrm{BE} \approx 284.6 \mathrm{eV}^{39}\right)$ in the case of the $266 \mathrm{~nm}$ irradiated sample, with respect to the other two films. Additionally, the O1s spectra in Figure 8 show that, after irradiation with 266 $\mathrm{nm}$, the film seems more oxidized compared to the film irradiated at $355 \mathrm{~nm}$, containing also various oxygen functional groups. In particular, in the film irradiated with $266 \mathrm{~nm}$, one peak appears at $\sim 530.5 \mathrm{eV}$, attributed to the $\mathrm{Cd}(\mathrm{OH})_{2}$ compound, ${ }^{40}$ one at $\sim 532.2 \mathrm{eV}$ which is due to $-\mathrm{C}=\mathrm{O}$ groups, and at $\sim 533.3 \mathrm{eV}$ attributed to the $\mathrm{C}-\mathrm{O}$ and/or $-\mathrm{C}-\mathrm{O}-\mathrm{Cd}$ bond. This is an indication of the formation of mixed $\mathrm{Cd}$ and polymer 


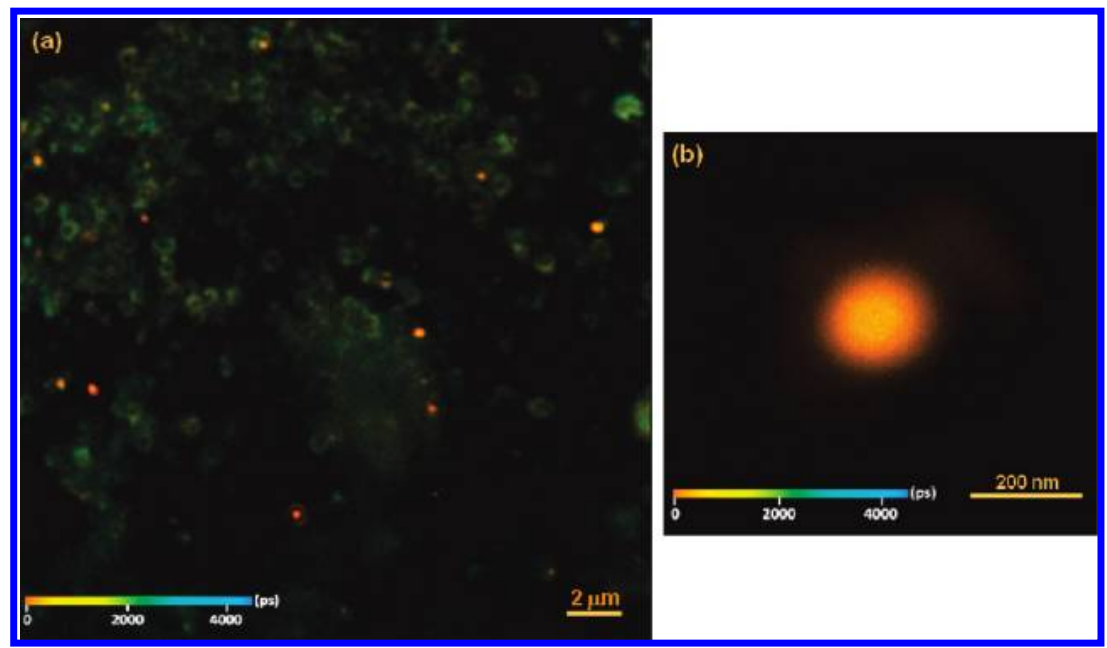

Figure 6. (a) Fluorescence lifetime topography of the CdS-PMMA blend film formed after irradiation with 2000 pulses of $355 \mathrm{~nm}$ of the C12-PMMA film. (b) Fluorescence lifetime image of a single NC.

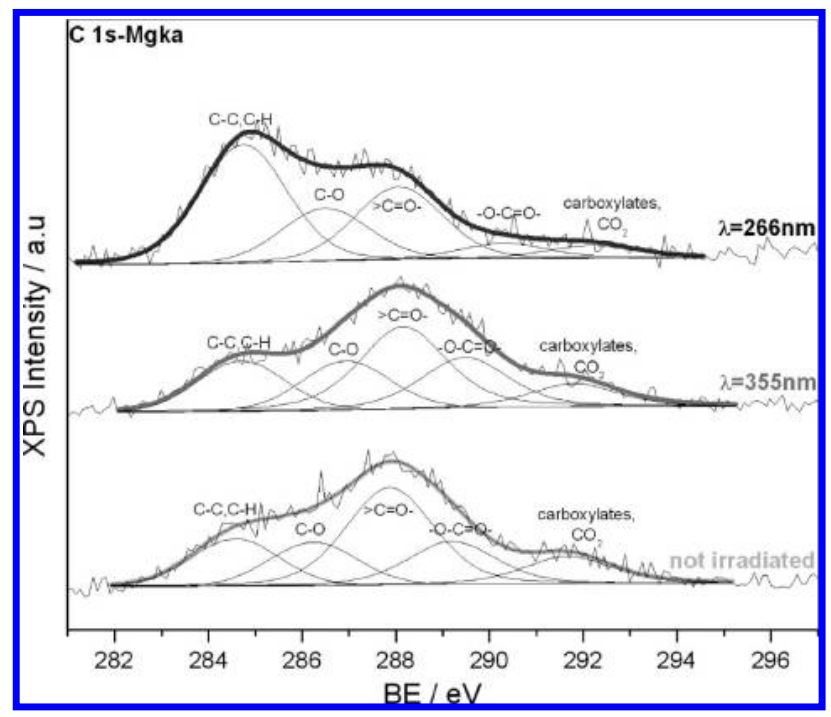

Figure 7. Deconvolution of the XPS C1s for the three studied films.

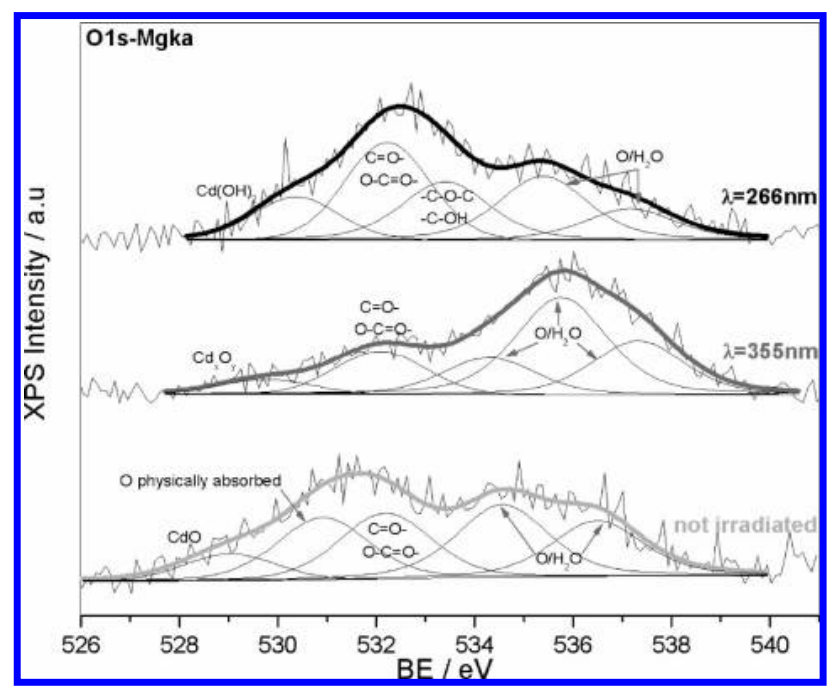

Figure 8. Deconvolution of the XPS O1s for the three studied films.

photoproduct configurations under $266 \mathrm{~nm}$ irradiation, leading possibly to enhanced trap states of the NCs.

On the other hand, in the spectrum obtained for the C12-PMMA film irradiated at $355 \mathrm{~nm}$, one peak appears at lower binding energy $(\sim 529.9 \mathrm{eV})$, which may be attributed to the formation of non-stoichiometric $\mathrm{Cd}_{x} \mathrm{O}_{y}$ compounds, and one at $\sim 532.2 \mathrm{eV}$ which is attributed to $-\mathrm{C}=\mathrm{O}$ groups. The $\mathrm{O} 1 \mathrm{~s}$ spectrum of the C12-PMMA film before any irradiation shows a contribution at $\sim 529.2 \mathrm{eV}$ attributed to $\mathrm{CdO}$ compound, ${ }^{41}$ indicating a small amount of oxidized precursor molecules, probably formed during their chemical preparation procedure. The peak at the $\sim 530.9 \mathrm{eV}$ is attributed to physically absorbed $\mathrm{O}$ on the surface of the film, and $\sim 532.2 \mathrm{eV}$ corresponds to the $-\mathrm{C}=\mathrm{O}$ groups of the PMMA matrix. The peaks at $\mathrm{BE}>534.5$ $\mathrm{eV}$, which appear in all the $\mathrm{O} 1 \mathrm{~s}$ spectra, correspond to absorbed $\mathrm{H}_{2} \mathrm{O}$ on their surfaces, possibly due to the chamber conditions or evaporation of solvent molecules trapped inside the films.

The above-mentioned results indicate that the $355 \mathrm{~nm}$ irradiation of the film affects slightly the chemical structure of the polymer chain, while the irradiation at $266 \mathrm{~nm}$ interacts strongly with the polymer creating various photoproducts, giving rise to different spectrum structure. Indeed, according to previous studies, ${ }^{42,43}$ the photodecomposition of the PMMA varies with the irradiation wavelength. Specifically, it has been shown, that, in the range of 315-400 nm, the PMMA does not undergo any degradation, while between 200 and $300 \mathrm{~nm}$, the photolysis of the polymer results in a random scission of the polymer chain backbone by a radical process, with a main role of the ester side-chain scission. The major initial products are the methyl formate radicals $\cdot \mathrm{COOCH}_{3}$, which abstract rapidly hydrogen atoms from the polymer backbone, forming methyl formates at room temperature. ${ }^{42,43}$

By combining the XPS with the emission results, it can be concluded that the CdS NCs formed upon irradiation with 355 $\mathrm{nm}$ exhibit very narrow emission spectra with low emission lifetime, even by increasing the incident pulses due to the absence of polymeric photoproducts in their environment. On the other hand, the irradiation at $266 \mathrm{~nm}$ causes an enhanced amount of photoproducts due to the polymer chain scission, and an intense oxidation of the formed CdS NCs. This results in the increase of the CdS trap states and, conclusively, the broadening of their emission and the prolongation of their fluorescence lifetime. Such a process is enhanced at higher laser fluence, since the polymer degradation is more intense and the surface defects of the CdS NCs are higher.

\section{Conclusions}

In this contribution we described the influence of the laser wavelength on the quality of bulk CdS NCs formed upon pulsed 
UV laser irradiation of a metal precursor embedded in a PMMA matrix. Using XPS and emission imaging analysis it is shown that the right combination of the irradiation wavelength with the polymer matrix can lead to the formation of high-quality of CdS NCs with small amount of trap states on their surface. Specifically, the irradiation at $355 \mathrm{~nm}$, although resulting in a slower CdS formation, gives NCs with higher emission quality compared to NCs from the irradiation at $266 \mathrm{~nm}$. In the latter case, the dominant emission comes from deep surface trap states, due to the interaction of the CdS NCs with the PMMA photoproducts caused by the photodegradation of its chain. In any case, the formed CdS NCs emitting at $500 \mathrm{~nm}$ have high quality in terms of surface defects since their fluorescence lifetime is in the range of $200 \mathrm{ps}$ at room temperature, a value really small compared to previously reported measurements. These findings are very important, concerning the patterned nanocomposite formation with size-tuned NCs, presented recently by our group, since it opens up the possibility for the generalization of the method, depending on the possible technological applications, by using various polymer matrices and irradiation conditions.

Acknowledgment. We thank Dr. A. M. Laera from ENEA, Centro Ricerche Brindisi, Italy, for the preparation of the precursor-polymer films and Dr. A. Siokou, principal researcher of the surface characterization laboratory of FORTH/HCE-HT, Patras Greece, where the XPS measurements were conducted.

Supporting Information Available: Figure S1: Emission spectra of C12-PMMA films irradiated at $355 \mathrm{~nm}$ (300 pulses and 3000 pulses) and $266 \mathrm{~nm}$ (10 pulses and 80 pulses) with fluence $F=20 \mathrm{~mJ} / \mathrm{cm}^{2}$. Figure S2: Fluorescence images and spectra of the C12-PMMA film irradiated with 3000 and 1000 pulses at $355 \mathrm{~nm}$ with fluence $65 \mathrm{~mJ} / \mathrm{cm}^{2}$. Figure S3: Fluorescence image and spectra of the C12-PMMA film after 3000 pulses at $355 \mathrm{~nm}$ with fluence $20 \mathrm{~mJ} / \mathrm{cm}^{2}$. Figure S4: Fluorescence lifetime topography of the CdS-PMMA film formed after irradiation with 40 pulses of $266 \mathrm{~nm}$ and fluence $F=50 \mathrm{~mJ} /$ $\mathrm{cm}^{2}$. This material is available free of charge via the Internet at http://pubs.acs.org.

\section{References and Notes}

(1) Brus, L. E. J. Phys. Chem. 1986, 90, 2555.

(2) Brus, L. E. J. Chem. Phys. 1984, 80, 4403.

(3) Nosaka, Y. J. Phys. Chem. 1991, 95, 5054.

(4) Wang, Y.; Herron, N. J. Phys. Chem. 1991, 95, 525.

(5) Henglein, A. Chem. Rev. 1989, 89, 1861.

(6) Xia, H.; Peng, J.; Liu, K.; Li, C.; Fang, Y. J. Phys. D: Appl. Phys. 2008, 41, 105405 .

(7) Medintz, I. L.; Tetsuouyeda, H.; Goldman, E. R.; Mattoussi, H. Nat. Mater. 2005, 4, 435.

(8) Bruchez, M., Jr.; Moronne, M.; Gin, P.; Weiss, S.; Alivisatos, A. P. Science 1998, 281, 2013.
(9) Michalet, X.; Pinaud, F. F.; Bentolila, L. A.; Tsay, J. M.; Doose, S.; Li, J. J.; Sundaresan, G.; Wu, A. M.; Gambhir, S. S.; Weiss, S. Science 2005, 307, 538.

(10) Lee, J.; Sundar, V. C.; Heine, J. R.; Bawendi, M. G.; Jensen, K. F. Adv. Mater. 2000, 12, 1102.

(11) Gaponik, N. P.; Talapin, D. V.; Rogach, A. L. Phys. Chem. Chem. Phys. 1999, 1, 1787.

(12) Sun, Z.-B.; Dong, X.-Z.; Chen, W.-Q.; Shoji, S.; Duan, X.-M.; Kawata, S. Nanotechnology 2008, 19, 035611.

(13) Mayer, A. B. R. Mater. Sci. Eng., C 1998, 6, 155.

(14) Tamborra, M.; Striccoli, M.; Comparelli, R.; Curri, M. L.; Petrella, A.; Agostiano, A. Nanotechnology 2004, 15, S240.

(15) Antolini, F.; Di Luccio, T.; Re, M.; Tapfer, L. Cryst. Res. Technol. 2005, 40, 948 .

(16) Di Luccio, T.; Laera, A. M.; Tapfer, L.; Kempter, S.; Kraus, R.; Nickel, B. J. Phys. Chem. B 2006, 110, 12603.

(17) Wang, C.; Yan, E.; Sun, Z.; Jiang, Z.; Tong, Y.; Xin, Y.; Huang, Z. Macromol. Mater. Eng. 2007, 292, 949.

(18) Athanassiou, A.; Cingolani, R.; Tsiranidou, E.; Fotakis, C.; Laera, A. M.; Piscopiello, E.; Tapfer, L. Appl. Phys. Lett. 2007, 91, 153108.

(19) Fragouli, D.; Laera, A. M.; Caputo, G.; Resta, V.; Pompa, P. P.; Tapfer, L.; Cingolani, R.; Athanassiou, A. J. Nanosci. Nanotechnol. 2010, $10,1267$.

(20) Fragouli, D.; Resta, V.; Pompa, P. P.; Laera, A. M.; Caputo, G.; Tapfer, L.; Cingolani, R.; Athanassiou, A. Nanotechnology 2009, 20, 155302.

(21) Fragouli, D.; Laera, A. M.; Pompa, P. P.; Caputo, G.; Resta, V.; Allione, M.; Tapfer, L.; Cingolani, R.; Athanassiou, A. Microelectron. Eng. 2009, 86, 816 .

(22) Nunes, P. S.; Ohlsson, P. D.; Ordeig, O.; Kutter, J. P. Microfluid. Nanofluid. 2010, 9, 145.

(23) Briggs, D., Seah, M. P., Eds. Practical Surface Analysis, 2nd ed.; John Wiley \& Sons: Australia1990.

(24) Wang, C.-W.; Moffit, M. G. Langmuir 2004, 20, 11784.

(25) Antoun, T.; Brayner, R.; Alterary, S.; Fiévet, F.; Chehimi, M.; Yassar, A. Eur. J. Inorg. Chem. 2007, 1275.

(26) Wu, F.; Zhang, J. Z.; Kho, R.; Mehra, R. K. Chem. Phys. Lett. 2000, 330, 237.

(27) Khanna, P. K.; Singh, N. J. Lumin. 2007, 127, 474.

(28) Mandal, D.; Chatterjee, U. J. Chem. Phys. 2007, 126, 134507.

(29) Klimov, V.; Haring Bolivar, P.; Kurz, H. Phvs. Rev. B 1996, 53, 1463.

(30) Chae, W.-S.; Shin, H.-W.; Lee, E.-S.; Shin, E.-J.; Jung, J.-S.; Kim, Y.-R. J. Phys. Chem. B 2005, 109, 6204.

(31) Garrett, M. D.; Dukes III, A. D.; McBride, J. R.; Smith, N. J.; Pennycook, S. J.; Rosenthal, S. J. J. Phys. Chem. C 2008, 112, 12736.

(32) Hoang, T. B.; Titova, L. V.; Mishra, A.; Smith, L. M.; Jackson, H. E.; Lee, K.-Y.; Rho, H.; Yarrison-Rice, J. M.; Choi, Y.-J.; Choi, K. J.;

Park, J.-G. Appl. Phys. Lett. 2008, 92, 143112.

(33) Heitz, R.; Hoffman, A.; Broser, I. Phys. Rev. B 1994, 49, 14307.

(34) Henry, C. H.; Nassau, K. Phys. Rev. B 1970, 1, 1628.

(35) Karan, S.; Mallik, B. J. Phys. Chem. C 2007, 111, 16734.

(36) Kumar, A.; Mital, S. J. Colloid Interface Sci. 2003, 265, 432.

(37) Ohara, Y.; Nakabayashi, T.; Iwasaki, K.; Torimoto, T.; Ohtani, B.;

Hiratani, T.; Konishi, K.; Ohta, N. J. Phys. Chem. B 2006, 110, 20927.

(38) Xu, Y.; Xia, J.; Hu, B. Prog. Org. Coat. 2009, 65, 25.

(39) Bayòn, R.; Maffiotte, C.; Herrero, J. Thin Solid Films 1999, 353, 100.

(40) El Maliki, H.; Bernede, J. C.; Marsillac, S.; Pinel, J.; Castel, X.; Pouzet, J. Appl. Surf. Sci. 2003, 205, 65.

(41) Singh, N.; Charan, S.; Patil, K. R.; Viswanath, A. K.; Khanna, P. K. Mater. Lett. 2000, 60, 3492.

(42) Cisse, A. L.; Grossman, E.; Sibener, S. J. J. Phys. Chem. B 2008, $112,7166$.

(43) Webb, R. L.; Langford, S. C.; Dickinson, J. T.; Lippert, T. K. Appl. Surf. Sci. 1998, 127, 815 .

JP103387A 